\title{
Comparison of Sodium Acid Sulfate and UV-C Treatment on Browning and Storage Quality of Fresh-Cut Potatoes
}

\author{
Yajing Xie, ${ }^{1}$ Qiong Lin, ${ }^{1}$ Wenqiang Guan, ${ }^{2}$ Shuzhen Cheng, \\ Zhidong Wang, ${ }^{1}$ and Chongde Sun ${ }^{3}$ \\ ${ }^{1}$ Institute of Food Science and Technology, Chinese Academy of Agricultural Sciences, \\ Key Opening Laboratory of Agricultural Products Processing and Quality Control, Ministry of Agriculture, Beijing 100193, China \\ ${ }^{2}$ Tianjin Key Laboratory of Food Biotechnology, College of Biotechnology and Food Science, \\ Tianjin University of Commerce, Tianjin 300134, China \\ ${ }^{3}$ Laboratory of Fruit Quality Biology, The State Agriculture Ministry Laboratory of Horticultural Plant Growth, \\ Development and Quality Improvement, Zhejiang University, Zijingang Campus, Hangzhou 310058, China
}

Correspondence should be addressed to Wenqiang Guan; gwq18@163.com and Zhidong Wang; wangzhidong@caas.cn

Received 17 March 2017; Accepted 14 May 2017; Published 30 July 2017

Academic Editor: Hui-Min D. Wang

Copyright (C) 2017 Yajing Xie et al. This is an open access article distributed under the Creative Commons Attribution License, which permits unrestricted use, distribution, and reproduction in any medium, provided the original work is properly cited.

Fresh-cut vegetables, such as potato chips, get brown quickly and can easily be infected by bacterium during storage. Sodium acid sulfate (SAS) and UV-C treatments are regarded as effective methods for food preservation. In this study, the effects of SAS, UV-C treatment, and their combination on fresh-cut potatoes during storage were evaluated. Compared with the control, all of the treatments were effective in inhibiting the bacterial growth during the whole storage period. Also, both SAS and SAS + UV-C treatments significantly decreased browning and polyphenol oxidase (PPO) activity and increased the firmness and malondialdehyde (MDA) contents, while the UV-C treatment has no good effects on protecting such storage qualities in freshcut potatoes. However, when compared with SAS treatment, the combination of SAS and UV-C treatment did not promote the effect in protecting the storage abilities. Thus, it was concluded that SAS is a better treatment in extending shelf life and controlling the quality of fresh-cut potatoes during storage compared to UV-C treatment.

\section{Introduction}

Fresh-cut vegetables, or minimally processed vegetables, are convenient for consumers while maintaining a high level of nutrients and a good taste [1]. However, these kinds of produces are easily suffering from browning, excessive microbe, and tissue softening due to the exposed surface. With an increasing share of the fresh-cut market during the last two decades, protecting the quality of produce has become particularly important $[2,3]$.

Discoloration is a consequence of imbalance between phenol and quinone metabolism, which occurs from breakdown of tissue integrity. Numerous technologies have been applied to extend shelf life of fresh-cut produce, particularly the physical methods, such as heat-shock [4], gamma irradiation [5], vacuum packaging [6], modified atmosphere packaging [7], and UV-C [8]. Among them, UV-C is an effective and widely used method in the storage of much fresh-cut produce. Previous reports showed that UV-C can reduce the bacterial population, control browning [9], and inhibit the polyphenol oxidase (PPO) activity [10]. In addition, it maintains nutrients, such as vitamin $\mathrm{D}_{2}$ [11], and can also lower the risk of disease [12]. Although UV-C has many advantages in protecting quality of fresh-cut produce, no significant effect on browning was observed according to previous reports [13].

Many chemical substances are regarded as effective colorpreserving reagents for fresh-cut vegetables, including ascorbic acid [14, 15], citric acid [16], ozone [17], calcium chloride $[18,19]$, and acidic electrolyzed water [20]. Sodium acid sulfate (SAS), which was certified as generally recognized as safe (GRAS) food additive by FDA in 1998, is effective 
in suppressing enzymatic browning and aerobic bacteria in fresh-cut apples [21], but the effects on potato chips are rarely investigated [22].

In the present study, the effects of SAS, UV-C, and their combination on browning, microbial growth, PPO activity, and malondialdehyde (MDA) content of fresh-cut potatoes during storage at $4^{\circ} \mathrm{C}$ were evaluated. The aim of this study was to provide better alternative method for postharvest storage of fresh-cut produce.

\section{Material and Methods}

2.1. Sample Preparation and Treatments. Potatoes were purchased from a local supermarket and used for all experiments. Potatoes of uniform size were selected, peeled, and cut into 4-5 mm slices using a slicer. Two pretests were conducted at $4^{\circ} \mathrm{C}$ to select the suitable treatment time and concentration. In order to select the optimum SAS concentration, the potato slices were dipped into $0 \%, 1.0 \%, 1.5 \%, 2.0 \%, 2.5 \%, 3.0 \%$, $4.0 \%$, and $5.0 \%$ SAS solutions for $2 \mathrm{~min}$, respectively. For the irradiation time of UV-C treatment, fresh-cut potatoes were irradiated for $2 \mathrm{~min}, 3 \mathrm{~min}, 4 \mathrm{~min}$, and $5 \mathrm{~min}$, respectively. After storage for a week, we found that UV-C irradiation for $3 \mathrm{~min}$ and $2.5 \%$ SAS treatment for $2 \mathrm{~min}$ were the most optimum selection.

Prepared potatoes were divided randomly into four groups: (a) control: untreated samples; (b) SAS treatment: dipped in $2.5 \%$ SAS solutions for $2 \mathrm{~min}$ and then wiped with a clean paper; (c) UV-C treatment: exposed to UV-C irradiation for $3 \mathrm{~min}$; (d) SAS + UV-C treatment: dipped in $2.5 \%$ SAS solutions for $2 \mathrm{~min}$ and then exposed to UV-C for $3 \mathrm{~min}$. After treatment, the fresh-cut potatoes were packaged in polyethylene bags and stored at $4^{\circ} \mathrm{C}$ for $25 \mathrm{~d}$. The potato slices were sampled at $0,5,10,13,16,19,22$, and $25 \mathrm{~d}$ after treatment. Each treatment was repeated for three times and each replication has three slices of potatoes.

2.2. Texture Analysis. Firmness of fresh-cut potatoes was measured using TA-XT2i texture analyzer (Stable Micro Systems Ltd., UK). The samples were indented with a compression probe P50 (Stable Micro Systems Ltd., UK) and firmness was taken as the maximum force $(\mathrm{N})$ required to puncture the slices for $70 \%$ of the thickness. Each slice was detected in two symmetrical points of the potato slices. Each treatment was repeated for six times.

2.3. Color Analysis. The color of the treated fresh-cut potatoes was measured using DigiEYE color Measurement and Imagine System (VeriVide Co. Ltd., Leicester, UK). Values of $L^{*}, a^{*}$, and $b^{*}$ were used for analysis. The results were expressed as mean value from the whole potato slices. Each treatment was replicated for six times.

2.4. PPO Activity Analysis. The PPO enzyme was extracted according to the PPO test kit (Bioengineering Institute, China) protocol. The PPO activity was determined as the amount of enzyme that caused the absorbance decrease of 0.01 at $525 \mathrm{~nm}$ for $1 \mathrm{~min}$.
2.5. Aerobic Plate Count (APC) Analysis. APCs were analyzed according to the method described in Chinese National Standards (GB 4789.2-2010) with modifications. All operations were conducted in sterile environment and all the reagents and instruments were sterilized $\left(121^{\circ} \mathrm{C}, 20 \mathrm{~min}\right)$ prior to the analysis. Potato slices were cut into cubes. $10 \mathrm{~g}$ aliquots of sample were transferred into a sterile stomacher bag (Beijing Medical, China), which contained $90 \mathrm{~mL}$ of sterile saline water, and then pummelled at maximum speed for $2 \mathrm{~min}$ by Lab-Blender BILON-08 (Shanghai Bilang Co. Ltd., China). The bacterium solution was diluted using sterile saline water to at least three dilutions based on the count of last period. $0.1 \mathrm{~mL}$ of each diluent was plated on plate count agar (Beijing, AoBoXing 02-035A, China). The plates were incubated at $37^{\circ} \mathrm{C}$ for $48 \mathrm{~h}$ and calculated as $\log \mathrm{CFU} \cdot \mathrm{kg}^{-1}$.

2.6. MDA Content. The MDA content was measured according to the method described by Lin et al. [23]. $1 \mathrm{~g}$ of prepared sample was homogenized with $5 \mathrm{~mL} 10 \%(\mathrm{w} / \mathrm{v})$ trichloroacetic acid and centrifuged for $10 \mathrm{~min}$ at $10,000 \mathrm{~g}$. $3 \mathrm{~mL} 0.6 \%$ thiobarbituric acid was added to the supernatant, and it was then held in a boiling water bath for $15 \mathrm{~min}$. Absorbance was measured at $450 \mathrm{~nm}, 532 \mathrm{~nm}$, and $600 \mathrm{~nm}$. The content of MDA was calculated as follows:

$$
\begin{aligned}
\operatorname{MDA}\left(\mu \mathrm{mol} \cdot \mathrm{L}^{-1}\right)= & 6.45 \times\left(A_{532}-A_{600}\right)-0.56 \\
& \times A_{450} .
\end{aligned}
$$

2.7. Statistical Analysis. All experiments were arranged in a completely randomized design and each treatment contained 3 replicates unless stated otherwise. Standard deviation and figures were drawn using Origin 8.6 (Microbial Software Inc., Northampton, MA, USA). The least significant difference (LSD) test at the 0.05 level was performed by SPSS Statistics 20 Software.

\section{Results}

3.1. Firmness. The variation in firmness of samples was relatively stable during the whole storage period. SAS and SAS + UV-C-treated samples had significant $(P<0.05)$ higher force values in firmness compared to control and UV-C-treated samples in most storage phases. No significant difference $(P>0.05)$ was found in firmness between UV-Ctreated samples and control during the whole storage period. At $5 \mathrm{~d}$ of storage, the firmness of potatoes in SAS + UV-C treatment increased by $74.9 \mathrm{~N}$ in comparison with that in SAS treatment. In general, the potatoes in SAS and SAS + UV-C treatments were firmer than that in control during the late storage period (Figure 1).

3.2. Color. Control and UV-C-treated potatoes showed an obviously darker appearance compared to SAS and SAS + UV-C-treated samples. The appearances of samples in SAS and SAS + UV-C treatments were similar during the whole storage period and were not affected by the length of the storage period. The UV-C-treated samples had no obvious 


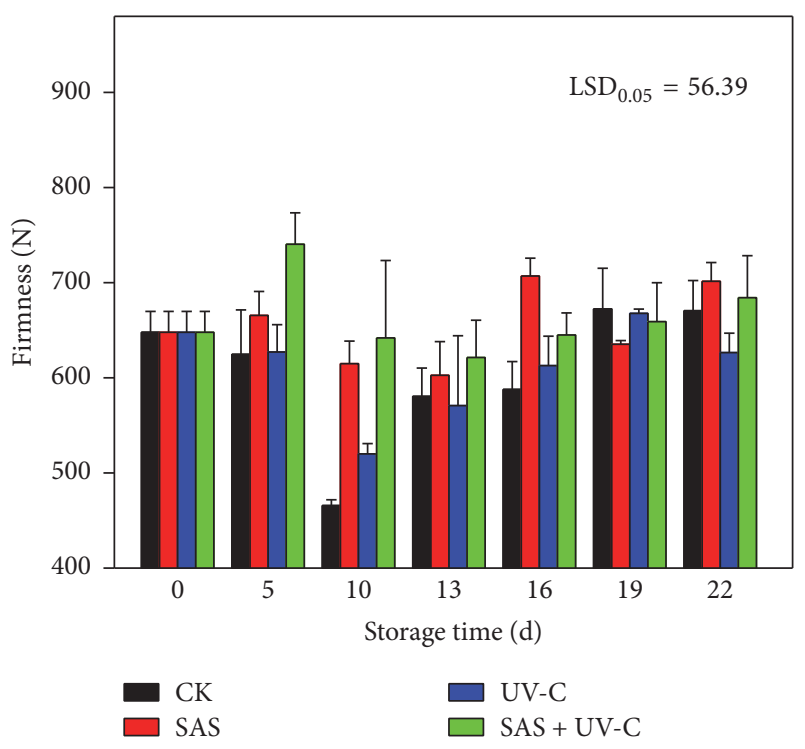

FIgURE 1: Effects of SAS, UV-C, and SAS + UV-C on firmness of fresh-cut potatoes during storage. The error bars represent the standard deviation. LSDs represent least significant differences at the 0.05 level.

difference with control, which appeared to lose its commodity attribute at $5 \mathrm{~d}$ storage (Figure 2).

$L^{*}, a^{*}$, and $b^{*}$ value of the fresh-cut potatoes are shown in Figure 3. Higher $L^{*}$ value represents lightness of the potato slices while decreasing $a^{*}$ indicates decline of redness, and increase in $b^{*}$ shows increasing yellowness of the potato slices.

$L^{*}$ values decreased continuously in the control and UV-C-treated potatoes. SAS and SAS + UV-C treatments maintained higher $L^{*}$ value compared with the control and UV-C-treated samples. However, no significant difference $(P>0.05)$ was observed between SAS and SAS + UV-C. After storage for 25 days, the $L^{*}$ value was decreased to 67.9 in control but was still maintained at 80.7 and 80.6 in SAS and SAS + UV-C-treated samples, respectively (Figure 3(a)).

The measurement of $a^{*}$ presented an increasing trend among all treatments. SAS and SAS + UV-C treatments significantly $(P<0.05)$ decreased $a^{*}$ value during the initial storage periods and the significant difference decreased as the storage period increased. At $10 \mathrm{~d}$ storage, $a^{*}$ value of potato slices in control was 15.7 and 6.70 times higher than that in SAS and SAS + UV-C treatment, respectively (Figure 3(b)).

The $b^{*}$ value presented a similar variation trend to $L^{*}$ value. Both SAS and SAS + UV-C treatments showed significantly $(P<0.05)$ higher $b^{*}$ value throughout whole storage compared to other treatments (Figure 3(c)).

3.3. $P P O$ Activity. $\mathrm{PPO}$ activity showed a high value in both the control and UV-C treatment during the storage period, but this phenomenon was significantly $(P<0.05)$ suppressed by SAS and SAS + UV-C treatment. PPO activity had no significant difference $(P>0.05)$ between UV-C treatment and the control during the early storage period, but it was significantly decreased $(P<0.05)$ by UV-C treatment at 13 , 16 , and $19 \mathrm{~d}$ of storage compared to the control. In addition, the PPO activity was significantly $(P<0.05)$ promoted by SAS + UV-C treatment at 10 and $13 \mathrm{~d}$ of storage compared to the SAS treatment (Figure 4).

3.4. Microbiological Analysis. The microbe count increased continuously in all the treatments during the whole storage period. SAS and SAS + UV-C treatments had significant effect on preventing bacterial growth during the whole periods while UV-C alone had significant result only in the later storage. SAS combined with UV-C treatment had the lowest bacterial populations among all treatments before storage of $13 \mathrm{~d}$, but the difference was not significant when compared to SAS treatment. At $25 \mathrm{~d}$, the APC in control samples was already too high to measure while it was maintained at $6.00 \log \mathrm{CFU} \cdot \mathrm{g}^{-1}$ approximately in the other three treatments (Figure 5).

3.5. MDA Content. The content of MDA presented an increasing trend on the whole. UV-C treatment showed no significant difference in MDA content of potatoes compared with the control. But the MDA content was immediately induced and increased by SAS and SAS + UV-C treatment and maintained a high level during the whole storage period. However, the increase of MDA content in potato was significantly suppressed by the combination of SAS and UV-C treatment (Figure 6).

\section{Discussion}

Fresh-cut products satisfy consumers as they are freshly prepared, convenient, and beneficial for human health. However, fresh-cut produce deteriorates faster than corresponding intact produce, which leads to a reduction in quality and shelf life. The key points in fresh-cut produce deterioration are discoloration and excessive microorganism growth during storage and transportation [24].

SAS has been reported to be an effective treatment for antibrowning of fresh-cut produce compared with other single or combined acidulants. Our results also suggested that $2.5 \%$ SAS significantly decreased the extent of browning in potato slices after $25 \mathrm{~d}$ storage, which confirmed the results of previous reports $[21,25,26]$. $\mathrm{PPO}$, a key regulation factor in the process of browning, catalyzed the oxidation reaction with oxygen and phenolic compounds and promoted accumulation of quinones, which react with other substances continually leading to the polymerization of quinones [27, 28]. Previous studies produced the low browning potato by silencing the PPO genes, and they confirmed four PPO gene members were closely related to browning of potatoes $[29,30]$. The maximum PPO activity in potato occurred at $\mathrm{pH} 6.8$, while it was nearly inactive when $\mathrm{pH}$ was below 4.0 [31]. Previous research has demonstrated that SAS is a stronger acidulant $(\mathrm{pKa}=2.0)$ when compared with ascorbic acid $(\mathrm{pKa}=4.1)$ and citric acid $(\mathrm{pKa}=3.1)$ [26]. There is a possibility that SAS treatment can decrease the $\mathrm{pH}$ level and 


\begin{tabular}{|c|c|c|c|}
\hline $\mathrm{CK}$ & UV-C & SAS & $\mathrm{SAS}+\mathrm{UV}-\mathrm{C}$ \\
\hline $0 \mathrm{~d}$ & & & \\
\hline $5 \mathrm{~d}$ & & & \\
\hline $10 \mathrm{~d}$ & & & \\
\hline $13 \mathrm{~d}$ & & & \\
\hline $16 \mathrm{~d}$ & & & \\
\hline $19 \mathrm{~d}$ & & & \\
\hline $22 \mathrm{~d}$ & & & \\
\hline $25 \mathrm{~d}$ & & & \\
\hline
\end{tabular}

FIGURE 2: Effects of SAS, UV-C, and SAS + UV-C on appearance of fresh-cut potatoes during storage.

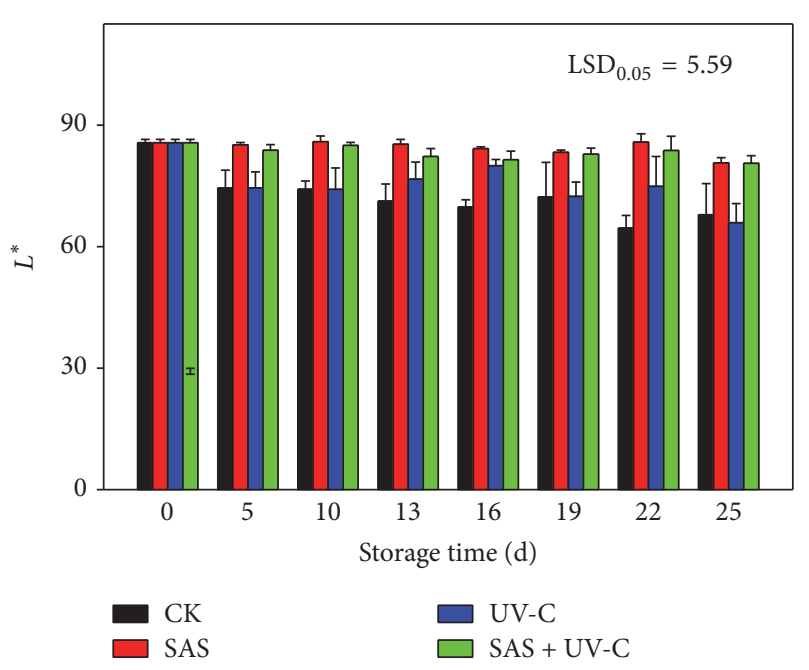

(a)

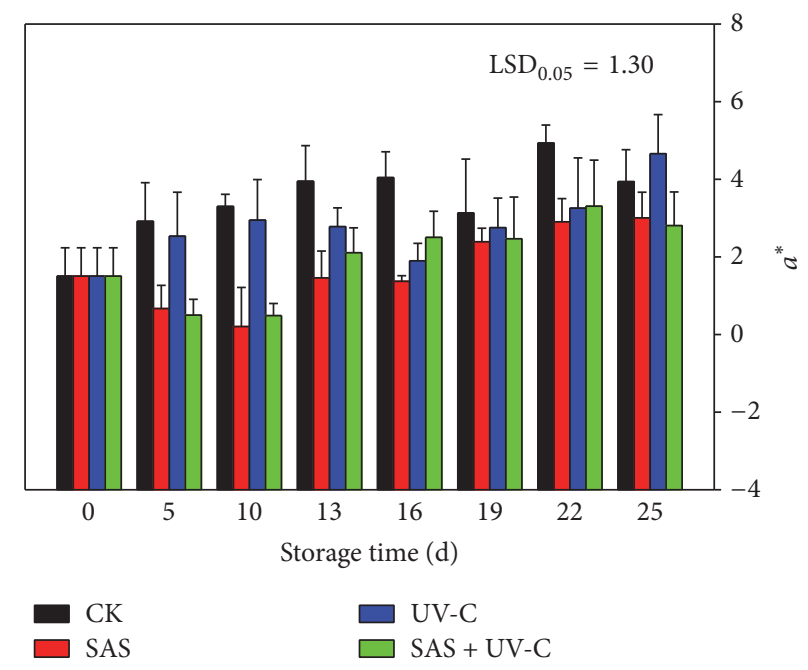

(b)

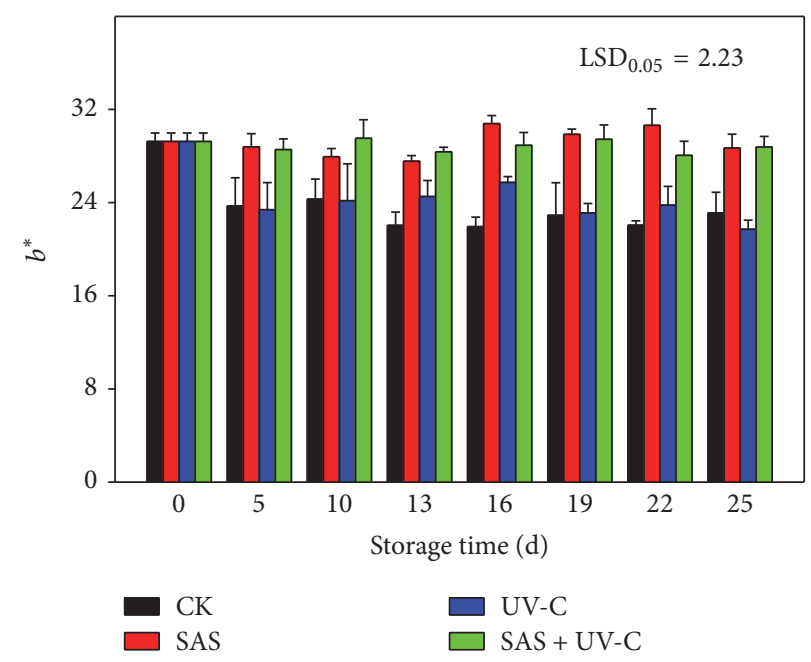

(c)

Figure 3: Effects of SAS, UV-C, and SAS + UV-C on color indexes of fresh-cut potatoes during storage. (a) $L^{*}$ value; (b) $a^{*}$ value; (c) $b^{*}$ value. The error bars represent the standard deviation. LSDs represent least significant differences at the 0.05 level. 


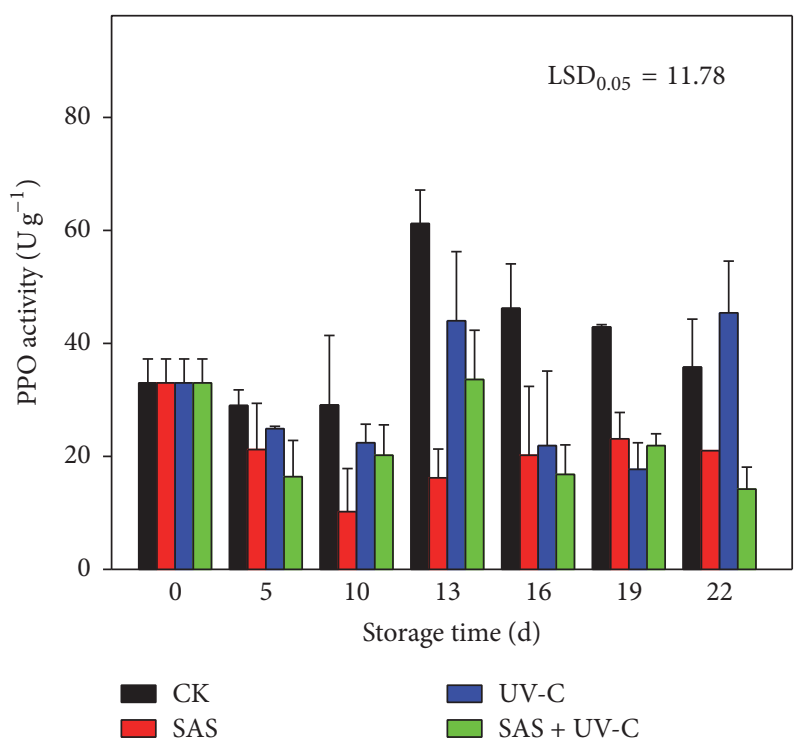

FIGURE 4: Effects of SAS, UV-C, and SAS + UV-C on PPO activity of fresh-cut potatoes during storage. The error bars represent the standard deviation. LSDs represent least significant differences at the 0.05 level.

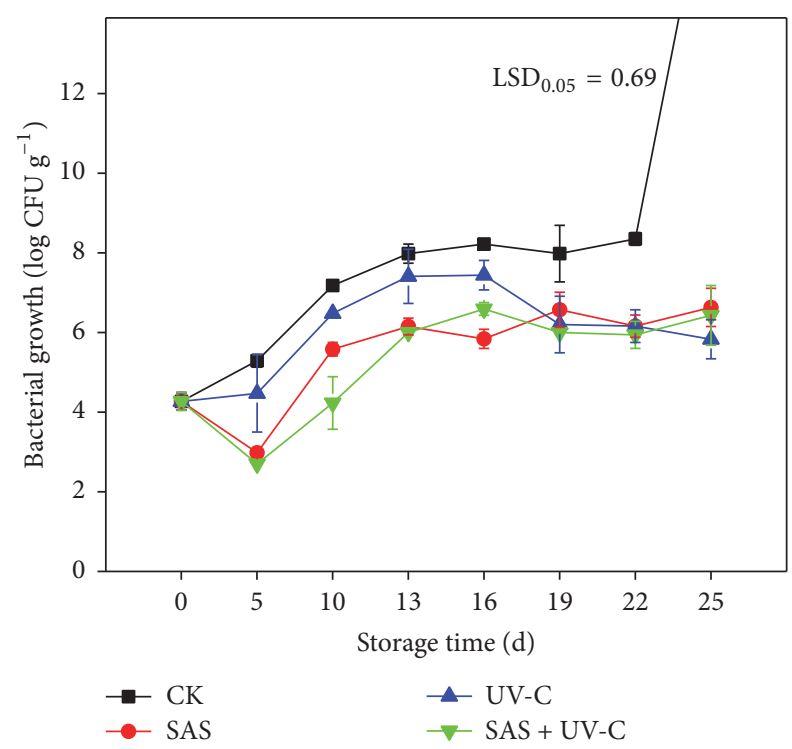

FIGURE 5: Effects of SAS, UV-C, and SAS + UV-C on APC of freshcut potatoes during storage. The error bars represent the standard deviation. LSDs represent least significant differences at the 0.05 level.

PPO activity of the potato tissues, thus, leading to alleviated surface browning.

Excessive microbial population in fresh-cut produce is another problem in fresh-cut industry $[32,33]$. UV-C is an environmental-friendly strategy for extending the shelf life of fresh-cut produce and has proved to be effective in reducing bacterial count but not damage other quality attributes [3436]. Our results showed that UV-C treatment was effective in sterilization of fresh-cut potatoes during storage, and, more interestingly, the SAS treatment had a better effect than UV-C

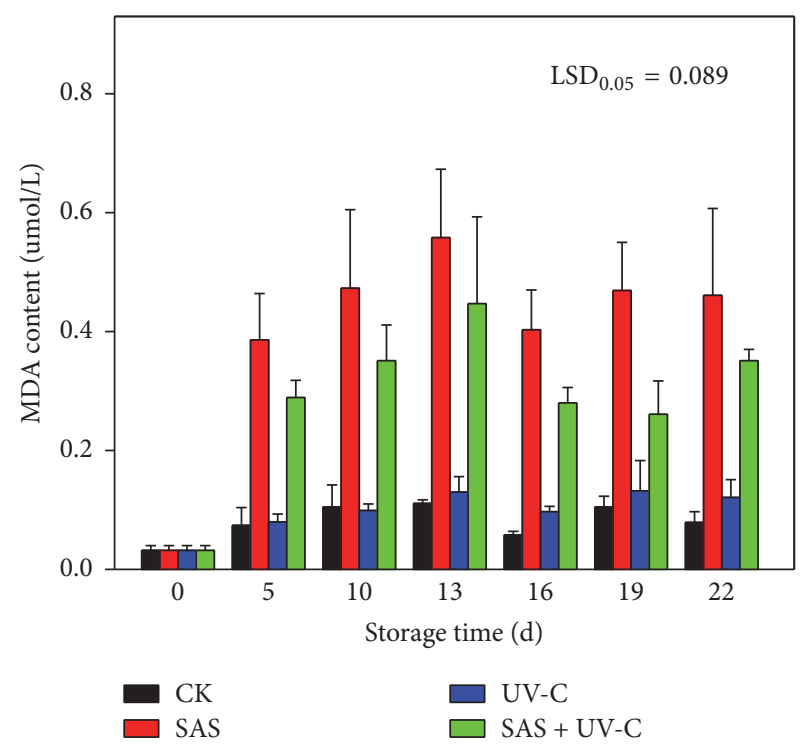

FIgURE 6: Effects of SAS, UV-C, and SAS + UV-C on MDA content of fresh-cut potatoes during storage. The error bars represent the standard deviation. LSDs represent least significant differences at the 0.05 level.

treatment during the early storage period. It was speculated that hydrogen sulfate ion and lower $\mathrm{pH}$ might be the main reasons for antimicrobial action in SAS treatment [21], but the regulation mechanism needs further research.

Combined treatments have been widely used in fresh produce during postharvest storage. For example, hot water combined with UV-C treatment has been applied to improve disease resistance and maintain quality of mangos [37]; aqueous chlorine dioxide combined with UV-C treatment was efficient in extending shelf life of blueberries [38]; UV$\mathrm{C}$ combined with heat treatment was efficient in inactivation of the spoilage yeasts in apple juice [39]. According to our results, no significant antibrowning or antimicrobial effect was observed in fresh-cut potato under SAS + UV$\mathrm{C}$ treatment compared with the SAS treatment; thus, it was concluded that SAS combined UV-C treatment did not promote the effect in protection of the storage abilities of fresh-cut potatoes.

In summary, SAS treatment was the most effective method in antibrowning and antimicrobial effects in freshcut potatoes during storage, and it was even better than the UV-C treatment. But combination of the selected SAS concentration and UV-C irradiation did not enhance the effects. In addition, the shelf life of fresh-cut potatoes can reach $22 \mathrm{~d}$ when SAS combined with UV-C, and it was maintained no more than $5 \mathrm{~d}$ when treated with control or UV-C alone. Thus, SAS is effective in controlling quality of fresh-cut produce during storage.

\section{Conflicts of Interest}

The authors declare that there are no conflicts of interest regarding the publication of this paper. 


\section{Authors' Contributions}

Yajing Xie and Qiong Lin contributed equally to this work.

\section{Acknowledgments}

This work was supported by the Young Scientist's Fund of National Natural Science Foundation of China (NSFC) (no. 31601527), the Agricultural Science and Technology Innovation Program (ASTIP) from the Chinese Central Government, and the National Natural Science Foundation of China (no. 31271949).

\section{References}

[1] M. I. Alarcón-Flores, R. Romero-González, J. L. M. Vidal, F. J. E. González, and A. G. Frenich, "Monitoring of phytochemicals in fresh and fresh-cut vegetables: A comparison," Food Chemistry, vol. 142, pp. 392-399, January 2014.

[2] E. Rytel, A. Tajner-Czopek, A. Kita, J. Miedzianka, and M. Bronkowska, "The influence of washing and selection processes on the contents of glycoalkaloid and other toxic compounds during industrial chip production," International Journal of Food Science and Technology, vol. 50, no. 8, pp. 1737-1742, August 2015.

[3] M. Cavaiuolo, G. Cocetta, R. Bulgari, A. Spinardi, and A. Ferrante, "Identification of innovative potential quality markers in rocket and melon fresh-cut produce," Food Chemistry, vol. 188, pp. 225-233, 2015.

[4] Q. Wang, X. Nie, and M. Cantwell, "Hot water and ethanol treatments can effectively inhibit the discoloration of fresh-cut sunchoke (Helianthus tuberosus L.) tubers," Postharvest Biology and Technology, vol. 94, pp. 49-57, August 2014.

[5] J. Pinela, J. C. M. Barreira, L. Barros et al., "Suitability of gamma irradiation for preserving fresh-cut watercress quality during cold storage," Food Chemistry, vol. 206, pp. 50-58, 2016.

[6] G. I. Denoya, S. R. Vaudagna, and G. Polenta, "Effect of high pressure processing and vacuum packaging on the preservation of fresh-cut peaches," LWT - Food Science and Technology, vol. 62, no. 1, pp. 801-806, 2015.

[7] J. Pinela, J. C. M. Barreira, L. Barros et al., "Postharvest quality changes in fresh-cut watercress stored under conventional and inert gas-enriched modified atmosphere packaging," Postharvest Biology and Technology, vol. 112, pp. 55-63, February 2016.

[8] P. L. Gómez, S. M. Alzamora, M. A. Castro, and D. M. Salvatori, "Effect of ultraviolet-C light dose on quality of cut-apple: Microorganism, color and compression behavior," Journal of Food Engineering, vol. 98, no. 1, pp. 60-70, 2010.

[9] W. Guan, X. Fan, and R. Yan, "Effect of combination of ultraviolet light and hydrogen peroxide on inactivation of Escherichia coli O157: H7, native microbial loads, and quality of button mushrooms," Food Control, vol. 34, no. 2, pp. 554-559, 2013.

[10] N. Pongprasert, Y. Sekozawa, S. Sugaya, and H. Gemma, "A novel postharvest UV-C treatment to reduce chilling injury (membrane damage, browning and chlorophyll degradation) in banana peel," Scientia Horticulturae, vol. 130, no. 1, pp. 73-77, 2011.

[11] W. Guan, J. Zhang, R. Yan et al., "Effects of UV-C treatment and cold storage on ergosterol and Vitamin D2 contents in different parts of white and brown mushroom (Agaricus bisporus)," Food Chemistry, vol. 210, pp. 129-134, 2016.

[12] K. Cools, M. D. C. Alamar, and L. A. Terry, "Controlling sprouting in potato tubers using ultraviolet-C irradiance," Postharvest Biology and Technology, vol. 98, pp. 106-114, December 2014.

[13] A. Meireles, E. Giaouris, and M. Simões, "Alternative disinfection methods to chlorine for use in the fresh-cut industry," Food Research International, vol. 82, pp. 71-85, 2016.

[14] M. Koushesh Saba and O. B. Sogvar, "Combination of carboxymethyl cellulose-based coatings with calcium and ascorbic acid impacts in browning and quality of fresh-cut apples," $L W T$ - Food Science and Technology, vol. 66, pp. 165-171, 2016.

[15] M. Zielinska, W. Blaszczak, and S. Devahastin, "Effect of superheated steam prefrying treatment on the quality of potato chips," International Journal of Food Science and Technology, vol. 50, no. 1, pp. 158-168, 2015.

[16] C. Chen, W. Hu, Y. He, A. Jiang, and R. Zhang, "Effect of citric acid combined with UV-C on the quality of fresh-cut apples," Postharvest Biology and Technology, vol. 115, no. 111, p. 151, May 2016.

[17] K. Y. Wei, A. Ali, and C. F. Forney, "Effects of ozone on major antioxidants and microbial populations of fresh-cut papaya," Postharvest Biology and Technology, vol. 89, pp. 56-58, March 2014.

[18] S. Albertini, A. E. Lai Reyes, J. M. Trigo, G. A. Sarriés, and M. H. F. Spoto, "Effects of chemical treatments on fresh-cut papaya," Food Chemistry, vol. 190, Article ID 17720, pp. 1182-1189, 2016.

[19] W.-W. Zheng, I.-J. Chun, S.-B. Hong, and Y.-X. Zang, "Quality characteristics of fresh-cut 'Fuji' apple slices from 1methylcyclopropene-, calcium chloride-, and rare earth-treated intact fruits," Scientia Horticulturae, vol. 173, pp. 100-105, 2014.

[20] J. Hao, H. Li, Y. Wan, and H. Liu, "Combined effect of acidic electrolyzed water (AcEW) and alkaline electrolyzed water (AlEW) on the microbial reduction of fresh-cut cilantro," Food Control, vol. 50, pp. 699-704, 2015.

[21] X. Fan, K. J. B. Sokorai, C.-H. Liao, P. Cooke, and H. Q. Zhang, "Antibrowning and antimicrobial properties of sodium acid sulfate in apple slices," Journal of Food Science, vol. 74, no. 9, pp. M485-M492, 2009.

[22] B. C. KIM, L. B. PERKINS, B. CALDER, L. A. LEBLANC, and R. J. BUSHWAY, "Comparison of the efficacy of sodium acid sulfate and citric acid treatments in reducing acrylamide formation in french fries," Tech. Rep., Technical Bulletin-Maine Agricultural and Forest Experiment Station, 2009.

[23] Q. Lin, Y. Xie, W. Liu et al., "UV-C treatment on physiological response of potato (Solanum tuberosum L.) during low temperature storage," Journal of Food Science and Technology, vol. 54, no. 1-7, pp. 55-61, 2017.

[24] G. A. Francis, A. Gallone, G. J. Nychas et al., "Factors Affecting Quality and Safety of Fresh-Cut Produce," Critical Reviews in Food Science and Nutrition, vol. 52, no. 7, pp. 595-610, 2012.

[25] B. L. Calder, E. A. Kash, K. Davis-Dentici, and A. A. Bushway, "Comparison of sodium acid sulfate to citric acid to inhibit browning of fresh-cut potatoes," Journal of Food Science, vol. 76, no. 3, pp. 164-169, 2011.

[26] B. L. Calder, D. I. Skonberg, K. Davis-Dentici, B. H. Hughes, and J. C. Bolton, "The Effectiveness of Ozone and Acidulant Treatments in Extending the Refrigerated Shelf Life of FreshCut Potatoes," Journal of Food Science, vol. 76, no. 8, pp. S492S498, 2011. 
[27] C. Queiroz, M. L. Mendes Lopes, E. Fialho, and V. L. ValenteMesquita, "Polyphenol oxidase: Characteristics and mechanisms of browning control," Food Reviews International, vol. 24, no. 4, pp. 361-375, 2008.

[28] L. Sheng, X. Zhou, Z. Y. Liu et al., "Changed activities of enzymes crucial to membrane lipid metabolism accompany pericarp browning in 'Nanguo' pears during refrigeration and subsequent shelf life at room temperature," Postharvest Biology \& Technology, vol. 117, pp. 1-8, 2016.

[29] C. W. B. Bachem, G.-J. Speckmann, C. G. Van der Linde Piet et al., "Antisense expression of polyphenol oxidase genes inhibits enzymatic browning in potato tubers," Bio/Technology, vol. 12, no. 11, pp. 1101-1105, 1994.

[30] M. Chi, B. Bhagwat, W. D. Lane et al., "Reduced polyphenol oxidase gene expression and enzymatic browning in potato (Solanum tuberosum L.) with artificial microRNAs," BMC Plant Biology, vol. 14, no. 1, article no. 62, 2014.

[31] K. Duangmal and R. K. Owusu Apenten, "A comparative study of polyphenoloxidases from taro (Colocasia esculenta) and potato (Solanum tuberosum var. Romano)," Food Chemistry, vol. 64, no. 3, pp. 351-359, 1999.

[32] C. Liu, T. Ma, W. Hu, M. Tian, and L. Sun, "Effects of aqueous ozone treatments on microbial load reduction and shelf life extension of fresh-cut apple," International Journal of Food Science and Technology, vol. 51, no. 5, pp. 1099-1109, May 2016.

[33] J. H. Moon, C.-H. Pan, and W. B. Yoon, "Drying characteristics and thermal degradation kinetics of hardness, anthocyanin content and colour in purple- and red-fleshed potato (Solanum tuberosum L.) during hot air drying," International Journal of Food Science and Technology, vol. 50, no. 5, pp. 1255-1267, May 2015.

[34] Y. Lu, J. Zhang, X. Wang et al., "Effects of UV-C irradiation on the physiological and antioxidant responses of button mushrooms (Agaricus bisporus) during storage," International Journal of Food Science and Technology, vol. 51, no. 6, pp. 15021508, June 2016.

[35] L. Urban, F. Charles, M. R. A. de Miranda, and J. Aarrouf, "Understanding the physiological effects of UV-C light and exploiting its agronomic potential before and after harvest," Plant Physiology and Biochemistry, vol. 105, pp. 1-11, August 2016.

[36] M. Ferrario, S. M. Alzamora, and S. Guerrero, "Study of pulsed light inactivation and growth dynamics during storage of Escherichia coliATCC 35218, Listeria innocua ATCC 33090, Salmonella Enteritidis MA44 and Saccharomyces cerevisiae KE162 and native flora in apple, orange and strawberry juicescerevisiae KE162 and native flora in apple, orange and strawberry juices," International Journal of Food Science and Technology, vol. 50, no. 11, pp. 2498-2507, November 2015.

[37] K. Sripong, P. Jitareerat, S. Tsuyumu et al., "Combined treatment with hot water and UV-C elicits disease resistance against anthracnose and improves the quality of harvested mangoes," Crop Protection, vol. 77, pp. 1-8, 2015.

[38] F. Xu, S. Wang, J. Xu, S. Liu, and G. Li, "Effects of combined aqueous chlorine dioxide and UV-C on shelf-life quality of blueberries," Postharvest Biology and Technology, vol. 117, pp. 125-131, 2016.

[39] M. Gouma, E. Gayán, J. Raso, S. Condón, and I. Álvarez, "Inactivation of spoilage yeasts in apple juice by UV-C light and in combination with mild heat," Innovative Food Science and Emerging Technologies, vol. 32, pp. 146-155, December 2015. 

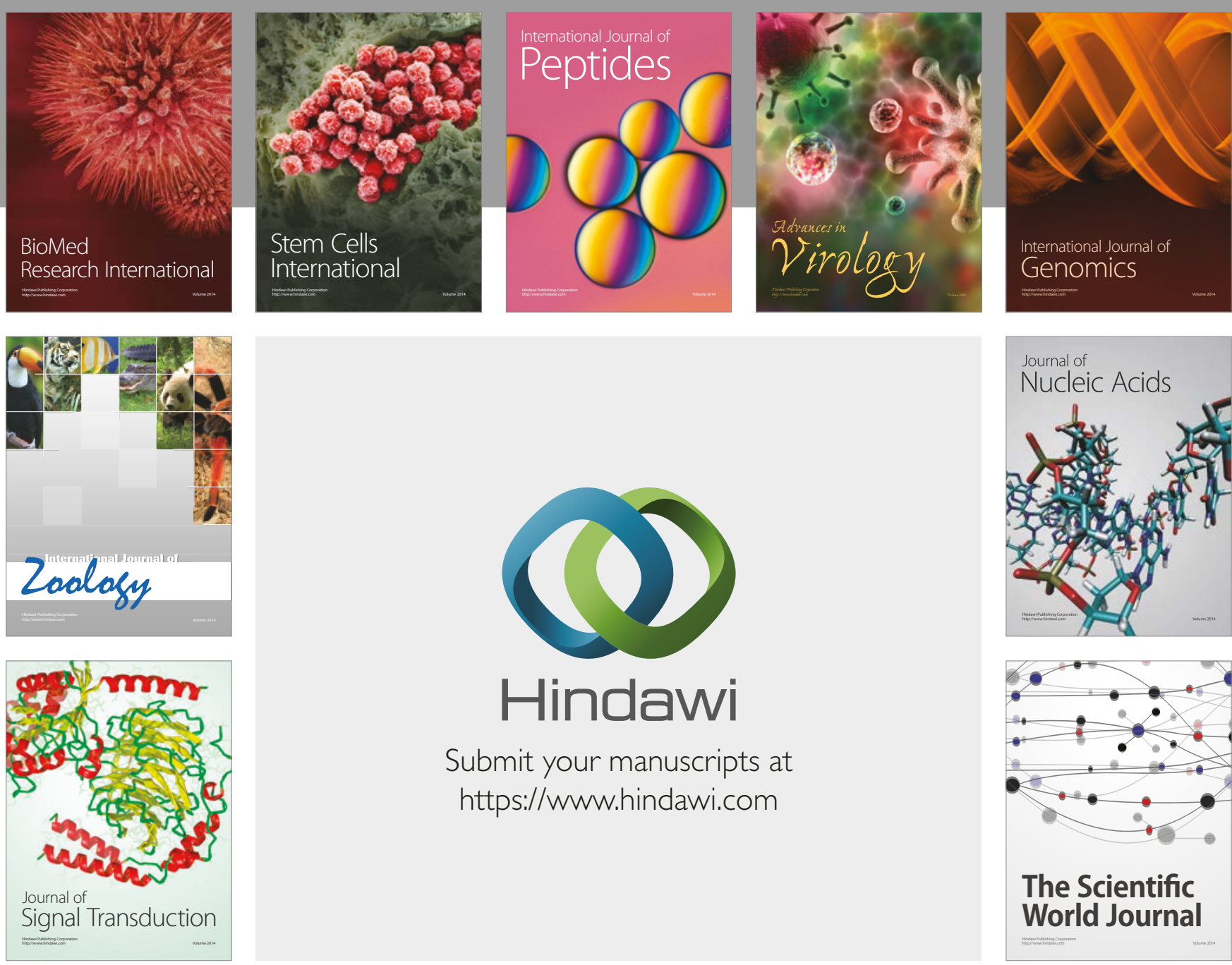

Submit your manuscripts at

https://www.hindawi.com
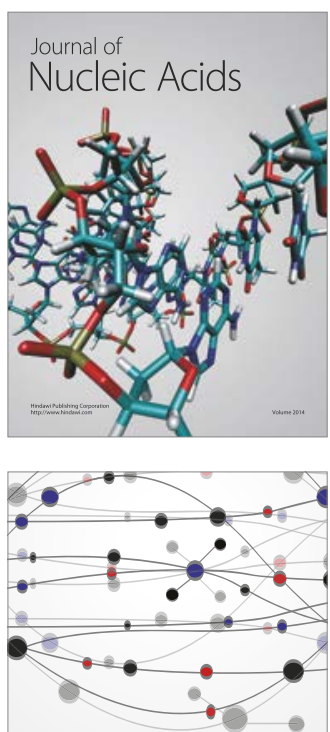

The Scientific World Journal

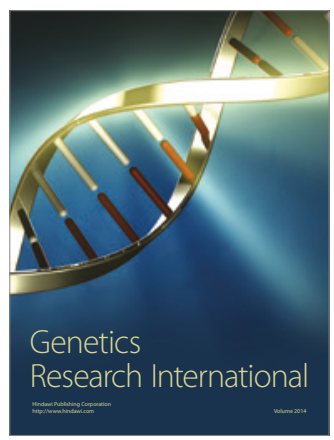

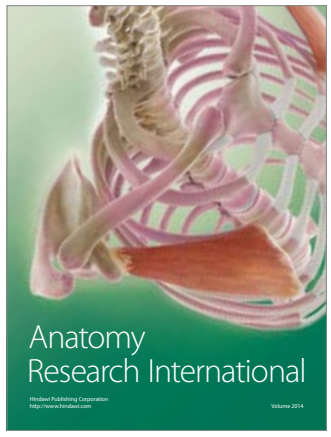

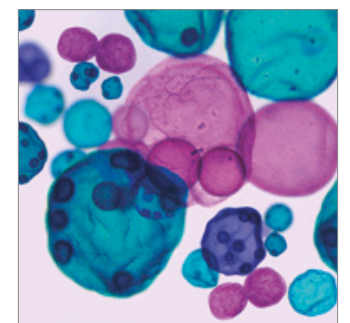

International Journal of Microbiology
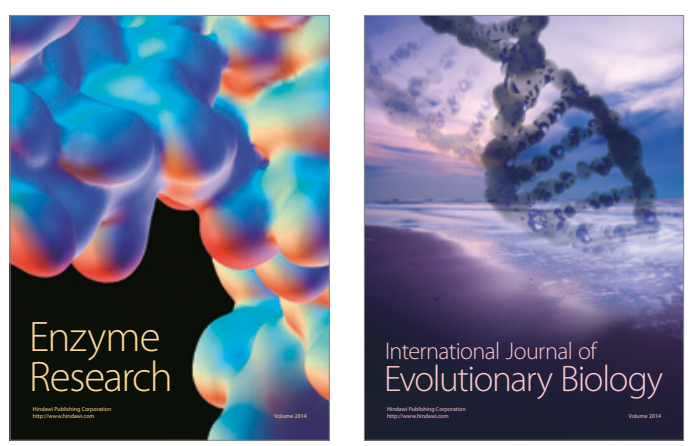
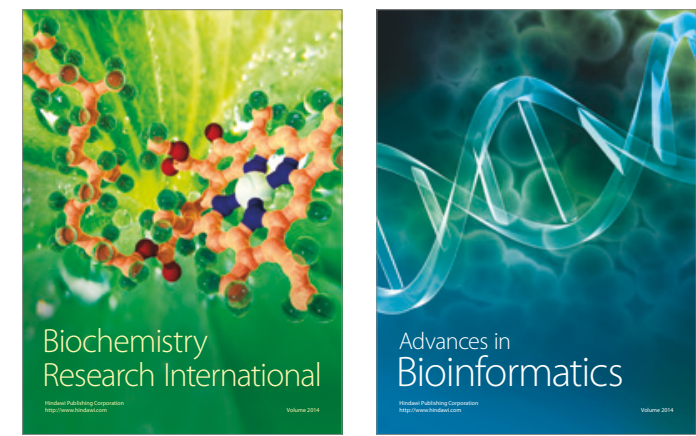

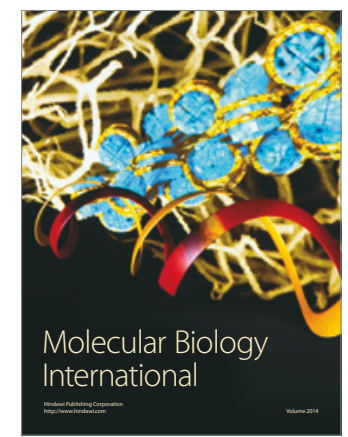

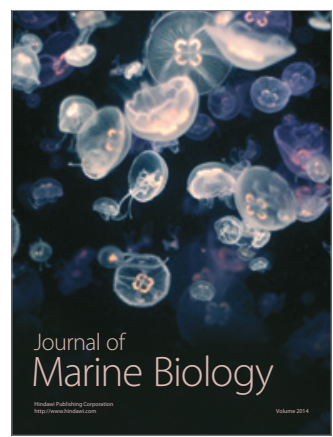

